\title{
Reproductive Health Knowledge of Rural Mothers of Hisar District, India
}

\author{
Poonam Malik* and Anju Aneja \\ Department of Human Development and Family Studies, I.C. College of Home Science, \\ CCS Haryana Agricultural University, Hisar-125004, Haryana, India
}

*Corresponding author

\section{Keywords}

Education level,

Family planning,

Infant mortality,

Reproductive

health,

Reproductive health

knowledge, Rural

mothers, Sexually

Transmitted

Diseases

\section{Article Info}

Accepted:

20 January 2019

Available Online:

10 February 2019

\section{A B S T R A C T}

The present study aimed at assessing levels of reproductive health knowledge of rural mothers. Reproductive health covers various aspects such as family planning, STD, AIDS, infant mortality, contraceptives, antenatal care etc. The sample consisted of 300 rural mothers, from Hisar district of Haryana state, having children below 5 years of age. The knowledge was assessed using Reproductive Health Knowledge Checklist developed under All India Coordinated Research Project, ICAR. The checklist categorized the knowledge levels as low, average and high. Information on personal variables of the respondents viz. education level, family income, husband's occupation, caste, number of children and newspaper subscription was obtained using a self- structured interview schedule. Frequencies, percentages, correlation and chi-square were used to analyze the data. Monthly income of most of the respondent was Rs.5000-Rs.20000. Most of them were educated up to matric or 10+2, belonged to SC/ST community, had four children and subscribed no newspaper. The level of reproductive health knowledge of majority of rural mothers was high and it was found to be positively and significantly correlated with their education level. Chi square test revealed that there was no significant association between reproductive health knowledge of mothers and their personal variables except their education level. So, it can be concluded that educated rural women have better knowledge of reproductive health.

\section{Introduction}

Reproductive health is of great importance for any society. Sound reproductive health prevents the spread of various sexually transmitted diseases such as AIDS, syphilis, etc. It also guarantees the production of better off springs having a better chance of survival.

According to World Health Organization website 'Reproductive health is a state of complete physical, mental and social well- being and not merely the absence of disease or infirmity, in all matters relating to the reproductive system and to its functions and processes. Reproductive health implies that people have the capability to reproduce and the freedom to decide if, when and how often to do so.'

WHO and the United Nations Interagency Working Group endorsed 17 indicators of the reproductive health situation at the global and national level. 
These indicators are-

\section{Total Fertility Rate (TFR)}

Total number of children a woman would have by the end of her reproductive period if she experienced the currently prevailing agespecific fertility rates throughout her childbearing life

\section{Contraceptive Prevalence Rate (CPR)}

Percent of women of reproductive age (15-49) who are using (or whose partner is using) a contraceptive method at a particular point in time

\section{Maternal Mortality Ratio (MMR)}

Annual number of maternal deaths per 100,000 live births

\section{Antenatal care coverage}

Percent of women attended at least once during pregnancy, by skilled health personnel (excluding trained or untrained traditional birth attendants), for reasons relating to pregnancy

Percent of births attended by skilled health personnel

Percent of births attended by skilled health personnel (excluding trained or untrained traditional birth attendants)

\section{Availability of basic essential obstetric care}

Number of facilities with functioning basic essential obstetric care per 500,000 population.

\section{Availability of comprehensive essential} obstetric care

Number of facilities with functioning comprehensive essential obstetric care per 500,000 population.

\section{Perinatal Mortality Rate (PMR)}

Number of perinatal deaths per 1,000 total births

\section{Low birth weight prevalence}

Percent of live births that weigh less than $2,500 \mathrm{~g}$

Positive syphilis serology prevalence in pregnant women

Percent of pregnant women (15-24) attending antenatal clinics, whose blood has been screened for syphilis, with positive serology for syphilis

\section{Prevalence of anemia in women}

Percent of women of reproductive age (15-49) screened for hemoglobin levels with levels $110 \mathrm{~g} / \mathrm{l}$ for pregnant women, and $120 \mathrm{~g} / \mathrm{l}$ for non-pregnant women

Percent of obstetric and gynecological admissions owing to abortion

Percent of all cases admitted to service delivery points providing in-patient obstetric and gynecological services, which are due to abortion (spontaneous and induced, but excluding planned termination of pregnancy)

\section{Reported prevalence of women with FGC}

Percent of women interviewed in a community survey reporting having undergone FGC.

\section{Prevalence of infertility in women}

Percent of women of reproductive age (15-49) at risk of pregnancy (not pregnant, sexually active, non-contracepting, and non-lactating) who report trying for a pregnancy for two years or more 


\section{Reported incidence of urethritis in men}

Percent of men aged (15-49) interviewed in a community survey reporting episodes of urethritis in the last 12 months

\section{HIV prevalence among pregnant women}

Percent of pregnant women (15-24) attending antenatal clinics, whose blood has been screened for HIV and who are sero-positive for HIV

\section{Knowledge of HIV-related prevention practices}

Percent of all respondents who correctly identify all three major ways of preventing the sexual transmission of HIV and who reject three major misconceptions about HIV transmission or prevention

Reproductive health knowledge includes knowledge about child care, family planning, dealing with sexual dysfunction and infertility, safe abortions, labour and delivery, postpartum care, treatment and prevention of Sexually Transmitted Diseases, AIDS, menstruation process etc. Good reproductive health knowledge means individual will have better chances of having good reproductive health. It also means better family planning and consequent prevention of unplanned pregnancies resulting in population explosion.

A study on family planning revealed that (i) Nearly one - third of all births is either undesired or unplanned, the major reason being the failure of contraceptive methods or accidental conception during lactation period;(ii) Strong preference for sons compels at least one- third of parents to go in for three or more number of children; (iii) Level of knowledge of various family planning methods like emergency contraceptives and no-scalpel vasectomy is low among the respondents; (iv) Desire to get vasectomy done is low among men; (v) Even after having three or more living children, only half of the men have any intention to adopt a permanent family planning method immediately or in future; and (vi) In half of the families, the husband is the sole decisionmaker regarding the number of children (Jayalakshmi et al., 2002).

Meena et al., (2015) in a study on Sexual and Reproductive Health (SRH) knowledge reported that young, unmarried, male residents of Delhi had good knowledge regarding HIV/AIDS, though their knowledge was found poor regarding other STIs/RTIs. Inadequate knowledge and negative attitude towards SRH and condom use were observed among rural participants. Peer group and mass media were the commonest SRH information sources among rural and urban participants, respectively.

Mittal (2018) concluded that India is lagging behind in guaranteeing right to health and reproductive rights as basic fundamental rights. The standard of reproductive health that is being provided in India to its women citizens is not enough to ensure right to life as a fundamental right and therefore the state needs to improve the implementation of its policies.

D'Souza et al., (2013) in a qualitative study of women's well-being and reproductive health status among married women in mining communities in India found that early marriage, increased fertility, less birth intervals, son preference and lack of decisionmaking regarding reproductive health choices affect women's reproductive health. Domestic violence, gender preference, husbands drinking behaviors, and low spousal communication were common experiences considered by women as factors leading to poor quality of marital relationship. Four 
main themes in confronting women's wellbeing are poor literacy and mobility, low employment and income generating opportunities, poor reproductive health choices and preferences and poor quality of martial relationships and communication.

D'Souza (2013) also reported that Cognitive, emotional and behavioural coping strategies are significant predictors of health related quality of life among Indian women in mining and agriculture.

Having knowledge of reproductive health logically means better chances of enjoying sound reproductive health. Present study was aimed at assessing the reproductive health knowledge of rural mothers and the association and relation of this knowledge with their personal variables.

\section{Materials and Methods}

\section{Locale of the study and sample selection}

The study was conducted at Hisar district of Haryana state. Five villages were selected purposively. From these villages, a total number of 300 young mothers having children below the age of 5 years were identified with the help of anganwadi workers. These 300 women constituted the sample for the study.

\section{Data collection}

A self structured interview schedule was prepared and used to collect information on personal variables. The Reproductive Health Knowledge Checklist was used for collecting information on reproductive health knowledge, which was prepared by expert scientists under All India Coordinated Research Project, ICAR. The checklist contained 33 statements covering different aspects of reproductive health. The response choices were yes, don't know and no which were scored as 2, 1 and zero respectively. Hence, the possible total score range was 066which was categorized as Low (0-22), Average (23-44) and High (45-66). The respondents, i.e. rural mothers, were approached personally by the respondents. The purpose of the study was explained to them. Their responses were recorded using the selected tools.

\section{Results and Discussion}

As shown in Table 1, $47.7 \%$ respondents had monthly family income of Rs. 10,000-Rs. 20,000 while it was Rs. 5,000-Rs.10,000 for an almost equal number of respondents (46\%). Only 5.7\% and $0.7 \%$ respondents had monthly family income above Rs. 20,000 and below Rs.5,000 respectively. Approximately one-third $(32.7 \%)$ of the mothers were matriculates while more or less a similar number $(29.7 \%)$ were educated up to senior secondary level. Out of total 300 rural mothers, $7.7 \%$ were illiterate, $14 \%$ were graduates and only $4 \%$ were post graduates. As far as the employment status of the husbands of these rural women is concerned, equal number were engaged in farming/selfemployment and private sector job $(32.7 \%$ each) while $28.7 \%$ were working as labourer. Majority of the rural mothers (64.3\%) belonged to SC/ST community followed by OBC $(21.3 \%)$ and General category (14.3\%). Out of 300 respondents, 39.3\% had four children, $27 \%$ had five children while $19.7 \%$ had three children. Only 9\% respondents had two children and 5\% were having a single child. Majority homes $(87.3 \%)$ were not subscribing any newspaper.

Reproductive health knowledge scores have been presented in Table 2. Reproductive health knowledge of majority of rural mothers (86.4\%) was high followed by 13.3 per cent mothers having average knowledge level. 
Only one of the 300 respondents (i.e. $0.3 \%$ ) had low level of reproductive health knowledge. The high scores of majority of rural mothers might be attributed to the efforts of Health Department as well as Department of Women and Child Development of
Haryana state. It was revealed during the course of personal discussions of the researchers with the respondents that health personnel and ICDS staff is regularly educating them about maternal and child health and nutrition.

Table.1 Personal variables of rural mothers N=300

\begin{tabular}{|c|c|c|}
\hline & Frequency & Percent \\
\hline \multicolumn{3}{|l|}{ Monthly Family Income (in Rs.) } \\
\hline Below 5000 & 02 & 0.7 \\
\hline $5000-10000$ & 138 & 46.0 \\
\hline $10000-20000$ & 143 & 47.7 \\
\hline 20000-50000 & 17 & 5.7 \\
\hline \multicolumn{3}{|l|}{ Education } \\
\hline Illiterate & 23 & 7.7 \\
\hline Primary & 01 & 0.3 \\
\hline Middle & 35 & 11.7 \\
\hline Matric & 98 & 32.7 \\
\hline Senior Secondary & 89 & 29.7 \\
\hline Graduation & 42 & 14.0 \\
\hline Post Graduation & 12 & 4.0 \\
\hline \multicolumn{3}{|l|}{ Husband's Occupation } \\
\hline Labourer & 86 & 28.7 \\
\hline Self Employed/Farmer & 98 & 32.7 \\
\hline Private Sector Job & 98 & 32.7 \\
\hline Temporary Government Job & 13 & 4.3 \\
\hline Permanent Government Job & 5 & 1.7 \\
\hline \multicolumn{3}{|l|}{ Caste } \\
\hline General & 43 & 14.3 \\
\hline OBC & 64 & 21.3 \\
\hline SC/ST & 193 & 64.3 \\
\hline \multicolumn{3}{|l|}{ No. of Children } \\
\hline 1 & 15 & 5.0 \\
\hline 2 & 27 & 9.0 \\
\hline 3 & 59 & 19.7 \\
\hline 4 & 118 & 39.3 \\
\hline 5 & 81 & 27.0 \\
\hline \multicolumn{3}{|l|}{ Newspaper Subscription } \\
\hline Yes & 38 & 12.7 \\
\hline No & 262 & 87.3 \\
\hline
\end{tabular}


Table.2 Reproductive health knowledge level of rural mothers $\mathrm{N}=300$

\begin{tabular}{|l|c|c|}
\hline $\begin{array}{l}\text { Level of Reproductive } \\
\text { Health Knowledge }\end{array}$ & Frequency & Percent \\
\hline $\begin{array}{l}\text { Low } \\
(\mathbf{0 - 2 2})\end{array}$ & 1 & 0.3 \\
\hline $\begin{array}{l}\text { Average } \\
(\mathbf{2 3 - 4 4 )}\end{array}$ & 40 & 13.3 \\
\hline $\begin{array}{l}\text { High } \\
(\mathbf{4 5 - 6 6 )}\end{array}$ & 259 & 86.4 \\
\hline
\end{tabular}

Table.3 Correlation of reproductive health knowledge with personal variables

\begin{tabular}{|l|c|}
\hline \multirow{2}{*}{ Variables } & $\begin{array}{c}\text { Reproductive Health Knowledge } \\
\text { ' } \mathbf{r} \text { ' values }\end{array}$ \\
\hline Monthly Family Income & .065 \\
\hline Education & $.225^{* *}$ \\
\hline No. of Children & .035 \\
\hline$* *$ Significant at $\mathrm{p}<.01$ & \\
\hline
\end{tabular}

Table.4 Association of personal variables with reproductive health knowledge

\begin{tabular}{|l|c|}
\hline \multirow{2}{*}{ Variables } & Reproductive Health Knowledge \\
\cline { 2 - 2 } & $\chi^{\mathbf{2}}$ values \\
\hline Monthly Family Income & 1.468 \\
\hline Education & $26.481^{*}$ \\
\hline Husband's Occupation & 8.051 \\
\hline Caste & 3.222 \\
\hline No. of Children & 12.677 \\
\hline Newspaper Subscription & 4.496 \\
\hline
\end{tabular}

*Significant at $\mathrm{p}<.05$

Correlations were computed between reproductive health knowledge of mothers and their monthly family income, education and no. of children. The ' $r$ ' values were .065 , $.225^{* *}$ and .035 respectively as shown in Table 3. It can be interpreted that reproductive health knowledge was positively correlated with all these three variables but the correlation was significant only in the case of education of the mothers which means that mothers having higher education level had higher reproductive health knowledge.
Chi-square was used to test the association between reproductive health knowledge and various personal variables of the respondents. As it is clear from Table 4, reproductive health knowledge was not found to be significantly associated with monthly family income $(\chi 2=1.468)$, husband's occupation $\left(\chi^{2}=8.051\right)$, caste $(\chi 2=3.222)$, no. of children $\left(\chi^{2}=12.677\right)$ and newspaper subscription $\left(\chi^{2}=\right.$ 4.496). However, significant association was observed between reproductive health knowledge and education level of rural mothers $(\chi 2=26.481 *)$. 
From the results of the study it can be concluded that health education helps women know about various aspects of reproductive health. However, the formal school and college education also has an impact on level of reproductive health knowledge of rural mothers. Probably educated mothers are more capable of and inclined to understand, interpret and retain this type of knowledge whenever and wherever they come across it.

\section{Acknowledgement}

The study was a part of All India Coordinated Research Project, ICAR. The investigators would like to thank ICAR for providing funds for this research. They would also like to thank the participants for their time and interest. They would also like to acknowledge the support given by ICDS functionaries and village panchayats. The infrastructural support provided by CCS Haryana Agricultural University is also acknowledged.

\section{References}

D'Souza M, Karkada S, Somayaji G, Venkatesaperumal R. 2013. Women's well-being and reproductive health in Indian mining community: need for empowerment. Reproductive Health. 10:1-12. doi: 10.1186/1742-4755-101.
D’Souza M, Karkada S, Somayaji G. 2013.Factors associated with healthrelated quality of life among Indian women in mining and agriculture. Health and Quality of Life Outcomes. 11:1-9. doi: 10.1186/1477-7525-11-1.

D’Souza M, Somayaji G, Subrahmanya N. 2011. Determinants of reproductive health and related quality of life among Indian women in mining communities. Journal of Advanced Nursing. $\quad 67: 1963-1975 . \quad$ doi: 10.1111/j.1365-2648.2011.05641.x.

Jayalakshmi, M.S., Ambwani, K., Prabhakar, P.K. and Swain, P.2002. A study of male involvement in family planning. Health and Population: Perspectives and Issues, 25(3), 113-123.

Meena, J.K., Verma, A., Kishore, J., and Ingle, G.K. 2015. Sexual and Reproductive Health: Knowledge, Attitude, and Perceptions among Young Unmarried Male Residents of Delhi. International Journal of Reproductive Medicine. Article ID 431460, 6 pages http://dx.doi.org/10.1155/2015/431460 Mittal, A. 2018. Reproductive Health Rights: A Case Study in India. World Journal of Public Health. 3(3), 99-104.

www.measureevaluation.org

www.who.int

\section{How to cite this article:}

Poonam Malik and Anju Aneja. 2019. Reproductive Health Knowledge of Rural Mothers of Hisar District. Int.J.Curr.Microbiol.App.Sci. 8(02): 2864-2870. doi: https://doi.org/10.20546/ijcmas.2019.802.336 